\title{
Social Learning Theory and the Health Belief Model
}

\author{
Irwin M. Rosenstock, $\mathbf{P h D}$ \\ Victor J. Strecher, PhD, MPH \\ Marshall H. Becker, PhD, MPH
}

The Health Belief Model, social learning theory (recently relabelled social cognitive theory), self-efficacy, and locus of control have all been applied with varying success to problems of explaining, predicting, and influencing behavior. Yet, there is conceptual confusion among researchers and practitioners about the interrelationships of these theories and variables. This article attempts to show how these explanatory factors may be related, and in so doing, posits a revised explanatory model which incorporates self-efficacy into the Health Belief Model. Specifically, self-efficacy is proposed as a separate independent variable along with the traditional health belief variables of perceived susceptibility, severity, benefits, and barriers. Incentive to behave (health motivation) is also a component of the model. Locus of control is not included explicitly because it is believed to be incorporated within other elements of the model. It is predicted that the new formulation will more fully account for health-related behavior than did earlier formulations, and will suggest more effective behavioral interventions than have hitherto been available to health educators.

\section{INTRODUCTION}

In recent years there has been a gradual development of models to explain and modify behavior. These models reflect a confluence of learning theories derived from two major sources: "Stimulus Response" (SR) theory ${ }^{1-3}$ and "Cognitive Theory". 4-9 SR theory itself represents a marriage of classical conditioning ${ }^{10}$ and instrumental conditioning ${ }^{1}$ theories.

In simplest terms, the SR theorists believe that learning results from events (termed "reinforcements") which reduce physiological drives that activate behavior. In the case of punishments. behavior that avoids punishment is learned because it reduces the tension set up by the punishment. The concept of drive reduction, however, is not

Irwin M. Rosenstock is FHP Endowed Professor and Director, Center for Health and Behavior Studies, California State University, Long Beach.

Victor J. Strecher is Assistant Professor, Department of Health Education, University of North Carolina.

Marshall H. Becker is Professor, Department of Health Behavior and Health Education, The University of Michigan.

Address reprint requests to Irwin M. Rosenstock, $\mathrm{PhD}$, Center for Health and $\mathrm{Be}-$ havior Studies, School of Applied Arts and Sciences, California State University, Long Beach, 1250 Bellflower Boulevard, Long Beach, CA 90840. 
necessary to the theory. Skinner ${ }^{11}$ formulated the widely accepted hypothesis that the frequency of a behavior is determined by its consequences (i.e., reinforcements). For Skinner, the mere temporal association between a behavior and an immediately-following reward is sufficient to increase the probability that the behavior will be repeated. Such behaviors are termed operants; they operate on the environment to bring about changes resulting in reward or reinforcement. In this view, no mentalistic concepts such as "reasoning" or "thinking" are required to explain behavior. While Skinner does not deny the existence of the mind, he believes that behavioral response can be fully explained by reinforcement contingencies alone.

Cognitive theorists emphasize the role of subjective hypotheses or expectations held by the subject. Behavior, in this perspective. is a function of the subjective value of an outcome and of the subjective probability (or "expectation") that a particular action will achieve that outcome. Such formulations are generally termed "valueexpectancy" theories. Reinforcements, or consequences of behavior, are believed to operate by influencing expectations (or hypotheses) regarding the situation.

\section{SOCIAL LEARNING THEORY}

The social learning theories of Rotter ${ }^{12}$ and Bandura ${ }^{13-15}$ reflect and are derived from these views. Bandura's social learning theory (SLT). ${ }^{13}$ which he has recently relabelled social cognitive theory (SCT). ${ }^{15}$ holds that behavior is determined by expectancies and incentives:

(1) Expectancies

For heuristic purposes these may be divided into three types:

(a) Expectancies about environmental cues (that is, beliefs about how events are connected-about what leads to what).

(b) Expectancies about the consequences of one's own actions (that is, opinions about how individual behavior is likely to influence outcomes). This is termed outcome expectation.

(c) Expectancies about one's own competence to perform the behavior needed to influence outcomes. This is termed efficacy expectation (i.e., self-efficacy).

(2) Incentives

Incentive (or reinforcement) is defined as the value of a particular object or outcome. The outcome may be health status. physical appearance, approval of others, economic gain, or other consequences. Behavior is regulated by its consequences (reinforcements), but only as those consequences are interpreted and understood by the individual.

Thus, for example, individuals who value the perceived effects of changed lifestyles (incentives) will at tempt to change if they believe that (a) their current lifestyles pose threats to any personally valued outcomes, such as health or appearance (environmental cues); (b) that particular behavioral changes will reduce the threats (outcome expectations); and (c) that they are personally capable of adopting the new behaviors (efficacy expectations). 


\section{THE HEALTH BELIEF MODEL}

The Health Belief Model (HBM) ${ }^{16-18}$ hypothesizes that health-related action depends upon the simultaneous occurrence of three classes of factors:

(1) The existence of sufficient motivation (or health concern) to make health issues salient or relevant.

(2) The belief that one is susceptible (vulnerable) to a serious health problem or to the sequelae of that illness or condition. This is often termed perceived threat.

(3) The belief that following a particular health recommendation would be beneficial in reducing the perceived threat, and at a subjectively-acceptable cost. Cost refers to perceived barriers that must be overcome in order to follow the health recommendation; it includes, but is not restricted to, financial outlays.

\section{THE HBM AND SCT}

We will hereafter use Bandura's preferred label of social cognitive theory (SCT) in comparing his concepts with the HBM. It has been noted by a number of authors ${ }^{19,20}$ that the HBM is closely related to SCT. This is hardly surprising because much of the development of "value-expectancy" theory (of which the Health Belief Model is an example) as well as social learning (or cognitive) theory builds upon the seminal work of Tolman ${ }^{5}$ and Kurt Lewin. ${ }^{6-9}$ Accordingly, considerable overlap should be expected.

The similarity of the HBM and Bandura's social cognitive concepts may be illustrated in the following diagram:

\section{CONCEPTS}

Social Cognitive Theory

Expectancies about environmental cues

Expectations about outcomes (Social Cognitive Theory does not explicitly include costs or barriers)

Expectations about self-efficacy

\section{Health Belief Model}

Perceived susceptibility to and severity of illness or its sequelae (threat)

Perceived benefits of taking a particular action minus perceived costs or barriers to action

(Not explicitly included in Health Belief Model though implied in "perceived barriers")

Health motive: value of reduction of perceived threats

Social cognitive theory has made at least two contributions to explanations of health-related behavior that were not included in the HBM. The first is the emphasis on the several sources of information for acquiring expectations, ${ }^{13,15}$ particularly on 
the informative and motivational role of reinforcement and on the role of observational learning through modeling (imitating) the behavior of others. The delineation of sources of expectations suggests a number of potentially-effective strategies for altering behavior through modifying expectations.

A second major contribution is the introduction of the concept of self-efficacy (efficacy expectation) as distinct from outcome expectation. ${ }^{13-15,21}$ Outcome expectation (defined as a person's estimate that a given behavior will lead to certain outcomes) is quite similar to the HBM concept of "perceived benefits." Efficacy expectation is defined as the conviction that one can successfully execute the behavior required to produce the outcomes. The distinction between outcome and efficacy expectations is important because both are required for behavior. The following diagram from Bandura ${ }^{13}$ shows the relationship:

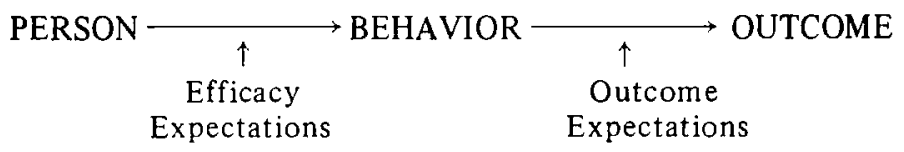

In order, say, for a woman (PERSON) to quit smoking (BEHAVIOR) for health reasons (OUTCOME), she must believe both that cessation will benefit her health (OUTCOME EXPECTATION) and also that she is capable of quitting (EFFICACY EXPECTATION).

\section{LOCUS OF CONTROL AND SELF-EFFICACY}

For Bandura, ${ }^{14}$ locus of control ${ }^{22}$ is not the same as self-efficacy, since the former is a generalized concept about the self. while the latter is believed to be siutationspecific-focused on beliefs about one's personal abilities in specific settings. Moreover, locus of control may relate more to outcome expectations than to efficacy expectations. In this view, internality reflects the opinion that personal behavior would influence outcomes. but disregards the question of whether one feels capable of performing that behavior. ${ }^{14}$ As Bandura puts it. "convictions that outcomes are determined by one's own actions can have any number of effects on self-efficacy and behavior. People who regard outcomes as personally determined but who lack the requisite skills would experience low self-efficacy and view activities with a sense of futility" (p. 204).

One may consider how different combinations of internality-externality and selfefficacy might influence compliance with a medical regimen (assuming optimal levels of incentive and perceived threat). In the $2 \times 2$ classification presented in Figure 1 , persons in cell $\mathrm{A}$ would be most likely to follow professional advice, while persons in cell D would be least likely to comply. Those in cell B believe themselves capable of undertaking the recommended behavior but will not do so because they are not convinced that the behavior will achieve some desired effect. People in cell $\mathrm{C}$ are those described in the quotation from Bandura - they believe outcomes are personally determined. but that they lack the skills to execute the action.

This analysis reveals that both internal locus of control (outcome expectation) and efficacy expectation are necessary for a given behavior to occur. When we turn from this overly simplified model of dichotomous expectations to the more realistic world 


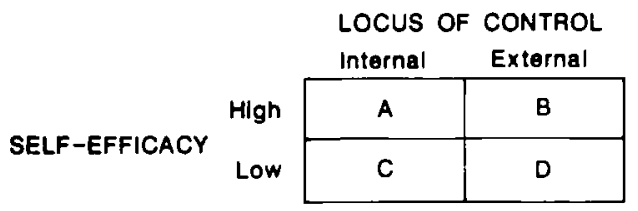

Figure 1. Combinations of Self-efficacy and Locus of Control

of continuously distributed expectations, the joint effects of the two dimensions become very complex indeed, and it is therefore not surprising that the multitude of studies on locus of control which disregard incentive, self-efficacy, and perceived threat have yielded inconsistent findings.

\section{CONTRIBUTION OF SELF-EFFICACY TO HBM}

The HBM has ignored efficacy expectations (in the Bandura definition) and thus may have failed to account for as much variance in behavior as it might. It is not difficult to see why self-efficacy was never explicitly incorporated into the HBM. The behavioral focus of the early Model was on circumscribed preventive actions, such as accepting immunizations, which generally were simple behaviors to perform except by those few persons with near-pathological fears of injections. Since it is likely that most prospective members of target groups for those programs had adequate self-efficacy for performing the recommended behavior, that dimension was never even recognized.

The situation is vastly different, however, in working with chronic illnesses, particularly those requiring long-term changes. The problems involved in modifying lifelong habits of eating, drinking, exercising, and smoking are obviously far more difficult to surmount than are those for accepting a one-time immunization or screening test. It requires a good deal of confidence that one can in fact alter such lifestyles before successful intervention is possible. Thus, for behavioral change to succeed, people must (as the HBM theorizes) have an incentive to take action, feel threatened by their current behavioral patterns and believe that change of a specific kind will be beneficial by resulting in a valued outcome at acceptable cost, but they must also feel themselves competent (self-efficacious) to implement that change. A growing body of literature supports the importance of self-efficacy in helping to account for initiation and maintenance of behavioral change, ${ }^{13-15,23}$ although only a few published studies have specifically addressed health-related lifestyle practices (see Strecher et al. ${ }^{21}$ for a review of these).

In a recent review documenting widespread empirical support for the HBM, Janz and Becker ${ }^{24}$ incorporate self-efficacy into the "barriers" component of the Model. While this represents a consistent use of the concept of "barriers," it may be a move in the wrong direction. "Perceived barriers" has always had something of a catch-all quality, including such disparate items as financial costs, phobic reactions, physical barriers. side-effects, accessibility factors, and even personality characteristics. Greater advances in explanation, prediction, and control will probably result from reducing, not increasing, the range of dimensions included in this concept. Making self-efficacy explicit in the HBM has two values: it delimits the barriers dimension; and, more importantly, suggests new and more-productive lines for research and practice. 


\section{CONTRIBUTION OF HBM TO SELF-EFFICACY THEORY}

While the failure to measure self-efficacy in earlier research on the HBM was certainly an important omission. it is also an error to stake as much on self-efficacy as many social learning theorists have recently attempted. Bandura's discussion ${ }^{14}$ seems to assume that the client who desires change possesses adequate incentives to change, feels sufficiently threatened by some potential or actual environmental event. fully believes outcomes can be influenced by behavior, and does not face major barriers to action. These are clearly important omissions. A number of reviews ${ }^{16-18.24-26}$ report findings from many studies that document people's failure to comply with medical advice or to take health-protective actions because they fail to exhibit much motivation (incentive) about health. because they do not think it particularly likely they will contract an ill-health condition or its sequelae, because they do not believe the occur. rence of the condition would seriously upset their lives, because they do not believe prevention or control of the condition is likely through personal intervention. or because they feel that the required effort on their part to avoid the problem exceeds the possible gain. These facts support the need to include the traditional components of the HBM in any comprehensive effort to under-stand and influence behavior. Selfefficacy theory. while representing an important step forward in our search for knowledge. can not replace the work that has preceded it. What began as a way of understanding and dealing with snake phobias must not be allowed to become snake oila patent medicine to cure all ills.

In a recent paper Strecher et al. $^{21}$ argue that outcome expectations and selfefficacy are both important determinants of health behavior; which is more important in a given case may depend on features of the situation such as the perceived difficulty of the behavior or the perceived certainty of its benefit. The interested reader should consult Strecher et al. ${ }^{21}$ for a more complete discussion of this point.

\section{ENHANCING SELF-EFFICACY}

Bandura ${ }^{15}$ argues that self-efficacy information derives from four sources: enactive, or performance attainments; vicarious experience; verbal persuasion; and physiological state.

Performance accomplishments are the most influential sources of efficacy information because they are based on personal mastery experience. Vicarious experience obtained through observation of successful or unsuccessful performance of others is next most potent and, indeed, may account for a major part of learning throughout life. Verbal persuasion (or exhortation) is frequently used in health education; while it is less powerful than performance accomplishments or vicarious experience. it can still be a useful adjunct to more-powerful influences. Of course, verbal persuasion may also influence outcome expectation or incentives. Finally, physiological states, particularly anxiety, may inform the individual, correctly or not. that he or she is not capable of performing or maintaining a given action-or success in eliminating negative affect may enhance one's self-efficacy.

Bandura. ${ }^{15}$ provides an example of how each of these sources of self-efficacy information can be employed by physicians to rehabilitate post-coronary patients. Performance information is provided through vigorous treadmill or other exercises. Vicari- 
ous efficacy information can be provided by enlisting former patients to serve as models of active lives. The physician also uses persuasive efforts to increase patients' convictions about their physical capabilities. Finally. physiological efficacy information is provided to ensure that patients do not misinterpret their physical status (e.g. incorrectly interpreting increased heart rates as foreshadowing another heart attack). If Bandura is right, the success of cardiac or other rehabilitation programs may depend as much on increasing self-efficacy to perform as on increasing physical ability to perform.

\section{PRACTICE IMPLICATIONS}

In planning programs, many health educators have found it useful to assess educational needs partly in terms of the beliefs described in the Health Belief Model. Thus. they seek to ascertain how many and which members of the target population are interested in health matters. feel susceptible to a serious health problem (or believe they currently have the problem). and believe that the threat could be reduced by some action on their part. at an acceptable cost. The assessment of such educational needs can be used to strengthen program planning and we encourage educators to continue to make such needs assessments. What we suggest in addition is that an important new piece of information be obtained-the extent to which patients or clients feel competent to carry out the prescribed action(s). sometimes over long periods of time and the strength of their conviction in their competence.

The collection of data on health beliefs, including self-efficacy, along with other data pertinent to the group or community setting permits the planning of more effective programs than would otherwise be possible. Interventions can then be targeted to the specific needs identified by such an assessment. For example. if we find that most people accept their susceptibility to cancer and fear the consequences of the disease while also believing that there are few cures for cancer, we can tailor interventions to increase perceived benefits (outcome expectations).

In the realm of chronic diseases. much more emphasis is likely to be needed on skill training to enhance self-efficacy. For example, behaviors that need to be acquired may be arranged in a series of steps of increasing difficulty, so that earlier tasks are more easily mastered than are later ones. With enhanced self-efficacy due to initial performance attainments, the person is more ready to take on tasks of greater complexity. Self-efficacy may thus be increased by setting short-term rather than long-term goals for some desired achievement. ${ }^{27,28}$

Patient-provider contracting may reflect a highly effective approach for enhancing self-efficacy. In the contingency contract, ${ }^{29}$ the patient and provider discuss and come to agree on a treatment goal, however modest; they agree on a time limit for its accomplishment; and both partners sign a document specifying the agreements. This technique is effective when properly used because the patient and provider are in a true therapeutic alliance, with both involved in choosing goals that the patient feels personally capable of achieving within the time limit. When the patient does accomplish the goal, the sense of self-efficacy in enhanced and the patient is ready to contract for a new, more-difficult goal. Whether or not the contract calls for a material reward seems of smaller consequence than the sense of pride and self-efficacy that accompanies achievement. 
The preceding examples are all in the realm of performance accomplishments, but health educators are also encouraged to use any of the other three sources of efficacy enhancement that may apply. Role models (vicarious experience) may be used to encourage imitation, exhortation may spur people on to initiate action or to reinforce their tentative first steps. Physiological and emotional effects such as smoking withdrawal symptoms may be anticipated, and methods sought to cope with them.

A strong emphasis on efficacy enhancement is not always required. As indicated earlier, where a health practice is inherently easy to accomplish (e.g., swallowing a tablet), no major concentration on efficacy is needed. But, where complex behavior patterns are required to maintain or restore health, enhancement of self-efficacy will usually be required. This would certainly appear to be the case in the acquisition or modification of complex lifestyle practices, including those related to smoking, alcohol and substance abuse, physical activity, and dietary habits.

\section{CONCLUSIONS}

In the history of attempts to explain. predict. and influence health-related behavior, the Health Belief Model has generated more research than any other theoretical approach. Its use has frequently yielded significant results, though the proportion of variance it explains, while variable across studies. is often lower than expected. This variability may be due to the failure to incorporate the self-efficacy concept into the Model. A comparison of Bandura's social learning theory (or "social cognitive theory" as he has recently relabeled it) with the HBM shows that the two theories have much in common-a not surprising finding, since both represent applications of valueexpectancy theories. Locus of control would appear to reflect outcome expectations or perception of benefits of taking particular courses of action.

Researchers and practitioners are urged to continue to use the Health Belief Model, but to incorporate self-efficacy both as an explanatory variable and as one that may be manipulated to good effect. Each of the sources of efficacy expectations provide points for potentially-effective interventions directed at behavioral modifications. In such attempts, however, one should not undervalue the importance of perceived benefits (outcome expectations).

We suggest that an expanded Health Belief Model which incorporates perceived selfefficacy will provide a more powerful approach to understanding and influencing health-related behavior than has been available to date.

\section{References}

1. Thorndike EL: Animal intelligence: an experimental study of the associative processes in animals. Psychological Monographs 2 (Whole No. 8), 1898.

2. Watson JB: Behaviorism. New York, Norton, 1925.

3. Hall CL: Principles of Behavior. New York, Appleton-Century-Crofts, 1943.

4. Kohler W: The Mentality of Apes. New York, Harcourt Brace, 1925.

5. Tolman EC: Purposive Behavior in Animals and Men. New York, Appleton-Century-Crofts, 1932.

6. Lewin K: A Dynamic Theory of Personality. New York, McGraw Hill Book Co., Inc., 1935. 
7. Lewin K: Principles of Topological Psychology. New York, McGraw Hill Book Co., Inc., 1936.

8. Lewin K, Dembo T, Festinger L, and Sears PS: "Level of aspiration." In J. Hunt (Ed.) Personality and the Behavior Disorders. New York, The Ronald Press, 1944, 333-378.

9. Lewin K: "The nature of field theory." In Marx MH (Ed.) Psychological Theory. New York: MacMillan, 1951.

10. Pavlov I: Conditional Reflexes. Oxford, Oxford University Press, 1927.

11. Skinner BF: The Behavior of Organisms. New York, Appleton-Century-Crofts, 1938.

12. Rotter JB: Social Learning and Clinical Psychology. New York, Prentice Hall, Inc., 1954.

13. Bandura A: Social Learning Theory. Englewood Cliffs, NJ, Prentice Hall, 1977.

14. Bandura A; Self-efficacy: Toward a unifying theory of behavioral change, Psychological Review 84:191-215, 1977.

15. Bandura A: Social Foundations of Thought and Action. Englewood Cliffs, NJ, Prentice Hall, 1986.

16. Rosenstock IM: Why people use health services, Milbank Memorial Fund Quarterly 44, 94-124, 1966.

17. Rosenstock IM: Historical origins of the health belief model, Health Education Monographs 2:328-335, 1974.

18. Becker MH (Ed.) The health belief model and personal health behavior, Health Education Monographs 2:324-473, 1974.

19. Maiman LA, Becker MH: The health belief model: Origins and correlates in psychological theory, Health Education Monographs 2:336-353, 1974.

20. Leventhal H, Meyer D, Gutman M: The role of theory in the study of compliance to high blood pressure regimens. In, Haynes B, Mattson ME, and Engelretson TO (eds.) Patient Compliance to Prescribed Antihypertensive Medication Regimens. USDHHS, NIH Pub. \#81-21002, October, 1980.

21. Strecher VJ, DeVellis BM, Becker MH, Rosenstock IM: The role of self-efficacy in achieving health behavior change, Health Education Quarterly, 13; 73-92, 1986.

22. Rotter JB: Generalized expectancies for internal versus external control of reinforcement. Psychological Monographs, 80, No. 1, 1966.

23. Schunk DH, Carbonari JP: Self-efficacy models, in Matarazzo, JD, Weiss SM, Herd JA, Miller NE, and Weiss SM (eds.) Behavioral Health New York. John Wiley \& Sons, Inc., 1984.

24. Janz NK, Becker MH: The health belief model: A decade later. Health Education Quarterly, 11:1-47, 1984.

25. Becker MH, Rosenstock IM: Compliance with medical advice. In Steptoe A and Matthews A (Eds.) Health Care and Human Behavior London, Academic Press, 1984.

26. Becker MH: Patient adherence to prescribed therapies Medical Care 23:539-555, 1985.

27. Bandura A, Schunk DH: Cultivating competence, self-efficacy, and intrinsic interest through proximal self-motivations. J Pers Soc Psychol 41:586-598, 1981.

28. Bandura A, Simon RM: The role of proximal intentions in self-regulation of refractory behavior. Cognitive Therapy and Research 1:177-193, 1977.

29. Janz NK, Becker MH, Hartman. PE: Contingency contracting to enhance patient compliance: A review. Patient Education and Counseling 5: 165-178. 